\title{
GAMBARAN KEPRIBADIAN KASIR SUPERMARKET DI PT XYZ
}

\author{
Octavianus Prabowo ${ }^{1}$, Zamralita $^{2}$ \\ ${ }^{1}$ Fakultas Psikologi, Universitas Tarumanagara Jakarta \\ Email: onuspra@gmail.com \\ ${ }^{2}$ Fakultas Psikologi, Universitas Tarumanagara Jakarta \\ Email: zamralita@fpsi.untar.ac.id
}

\begin{abstract}
ABSTRAK
Salah satu posisi penting di sebuah supermarket termasuk di PT XYZ adalah posisi kasir. Posisi ini dianggap penting, karena kasir merupakan muara atau akhir dari pengalaman berbelanja pelanggan di sebuah supermarket. Hal ini membuat seluruh pelanggan yang berbelanja dipastikan berinteraksi dengan kasir. Kasir di PT XYZ secara umum memiliki tugas utama yaitu melakukan pelayanan transaksi belanja pelanggan dan memastikan jumlah uang modal dan hasil pendapatan. Untuk dapat menjalankan pekerjaannya dengan baik, peneliti menduga kasir harus memiliki karakteristik kepribadian tertentu yang sesuai dengan bidang pekerjaannya. Penelitian ini bertujuan untuk memeroleh gambaran kepribadian kasir supermarket di PT XYZ. Teori yang digunakan adalah trait kepribadian dari Costa dan McCrae (1992) yang terdiri dari 5 trait yaitu trait openness to experience, trait conscientiousness, trait extraversion, trait agreeableness, dan trait neuroticism. Metode yang digunakan dalam penelitian ini metode kuantitatif. Responden penelitian adalah 154 orang kasir di PT XYZ yang tersebar di toko Jakarta, Tangerang, dan Bekasi. Hasil penelitian menunjukkan Kasir di PT XYZ memiliki trait extraversion yang tinggi $(M=3,20)$, trait conscientiousness yang tinggi $(M=3,17)$, trait openness to experience pada kategori rendah $(M=2,98)$, trait agreeableness yang rendah $(M=2,78)$, dan trait neuroticism yang rendah $(M=2,57)$.
\end{abstract}

Kata Kunci: Trait kepribadian, Kasir, Supermarket

\section{PENDAHULUAN}

Salah satu posisi penting di sebuah supermarket adalah posisi kasir. Posisi ini dianggap penting, karena kasir merupakan muara atau akhir dari pengalaman berbelanja pelanggan di sebuah supermarket. Hal ini membuat seluruh pelanggan yang berbelanja dipastikan berinteraksi dengan kasir. Kasir memiliki tanggung jawab utama untuk melakukan proses transaksi belanja pelanggan dengan baik dan tetap memerhatikan pelayanan pada pelanggan (senyum, sapa, salam). Pentingnya keberadaan kasir juga terjadi di PT XYZ yang merupakan perusahaan retail terkemuka di Indonesia yang berdiri sejak tahun 1998 dan memiliki supermarket dengan brand X dan Y. Sebagai perusahaan retail yang mengutamakan pelayanan pada pelanggan tentunya PT $\mathrm{XYZ}$ sangat bergantung pada kinerja para staff operasional tokonya termasuk kasir. Kasir di PT $\mathrm{XYZ}$ secara umum memiliki tugas utama yaitu melakukan pelayanan transaksi belanja pelanggan dan memastikan jumlah uang modal serta hasil pendapatan. Pelayanan yang diberikan tentunya agar pelanggan yang berkunjung ke toko merasa terbantu, puas, dan pada akhirnya kembali lagi untuk berbelanja. Hal ini sesuai dengan visi, misi, dan nilai PT XYZ yaitu berusaha untuk memuaskan dan menyenangkan pelanggan dengan memberikan pelayanan yang prima, dengan demikian tujuan dari perusahaan akan tercapai.

Perilaku kerja seseorang memiliki hubungan dengan kepribadian. Kepribadian seseorang dan identitasnya akan membedakannya dari orang lain, dan ini dibuktikan dengan kecenderungan untuk berpikir, merasakan, dan bertindak dengan cara tertentu sesuai kepribadiannya (Giffen, 2015). Hal ini didukung beberapa penelitian yang menunjukkan hubungan antara kepribadian dengan perilaku kerja. Penelitian oleh Rothmann dan Coetzer (2003) menemukan bahwa 
dimensi kepribadian neuroticism, extraversion, openness to experience dan conscientiousness berhubungan dengan performa kerja dan kreativitas.

Penelitian lainnya yang dilakukan Kovach, Simpson, Reitmaier, Johnson, dan Kelber (2010) pada 177 orang perawat menunjukkan secara keseluruhan, 21,3\% varians dalam kepuasan kerja perawat dijelaskan oleh kepribadian.

Opie dan Henn (2013) melakukan penelitian terhadap 267 orang Ibu yang bekerja di Afrika Selatan, hasilnya menunjukkan bahwa conscientiousness secara positif memprediksi keterikatan kerja, dan neuroticism secara negatif memprediksi keterikatan kerja. Efek interaksi yang signifikan ditemukan pada dimensi kepribadian conscientiousness. Penelitian yang dilakukan Arora dan Rangnekar (2016) pada 254 orang pekerja di India menunjukkan bahwa kepribadian conscientiousness dan agreeableness sebagai prediktor yang signifikan terhadap komitmen untuk berkarir.

Berdasarkan penelitian-penelitian tersebut dapat terlihat pentingnya kepribadian dalam memprediksi perilaku kerja seseorang. Perilaku kerja positif seperti komitmen karir, kepuasan kerja, performa kerja, dan keterikatan kerja ternyata dapat diprediksi oleh kepribadian seseorang. Peneliti menduga bahwa kasir memiliki gambaran kepribadian tertentu yang sesuai dengan sifat/karakteristik pekerjaannya untuk dapat menjalankan pekerjaannya dengan baik. Penelitian ini dilakukan untuk mendapatkan gambaran mengenai kepribadian kasir di PT XYZ.

\section{Teori}

Menurut Feist dan Feist (2006) kepribadian adalah pola sifat (watak) dan sebuah karakter unik, yang memberikan konsistensi sekaligus individualitas bagi perilaku seseorang. Costa dan McCrae melakukan factor analysis dalam menguji stabilitas dan struktur dari kepribadian, awalnya mereka berfokus pada dua dimensi utama, yaitu Neuroticism dan Extraversion. Dalam perjalanan waktu, mereka menemukan faktor ketiga yang mereka sebut dengan Openness to experience. Pada tahun 1985, ditemukan dua dimensi lainnya, yakni Agreeableness dan Conscientiousness.

Secara lebih spesifik lima trait kepribadian ini adalah Neuroticism misalnya kecenderungan untuk mudah stress dan cemas, Extraversion misalnya kecenderungan untuk senang mendapatkan perhatian dan sering mengalami suasana hati yang positif, Openness to experience misalnya ditunjukkan dengan keingintahuan, kreativitas, dan imajinasi yang tinggi, Agreeableness misalnya kecenderungan pro-sosial seperti mudah percaya, patuh, dan rendah hati, dan Conscientiousness misalnya memiliki kemauan untuk mencapai sesuatu dan kemampuan untuk mengendalikan diri (Costa \& McCrae, dalam Feist \& Feist, 2006).

\section{METODE PENELITIAN}

Metode dari penelitian ini adalah penelitian kuantitatif. Karakteristik responden dalam penelitian ini adalah kasir yang bekerja di PT XYZ, baik di supermarket X maupun Y yang tersebar di Jakarta, Tangerang, dan Bekasi. Teknik sampling yang digunakan dalam penelitian ini adalah non probability sampling, convenience sampling. Variabel dalam penelitian ini adalah Kepribadian. 
Data didapatkan dengan menyebarkan kuesioner penelitian kepada kasir yang bekerja di PT XYZ, laki-laki dan perempuan.

Kuesioner penelitian yang digunakan adalah tes lima dimensi yang dibuat oleh Sumintardja (2009). Tes lima dimensi memiliki nilai reliabilitas yang cukup baik untuk setiap dimensinya. Nilai koefisien reliabilitas internal dari dimensi trait Openness to experience $=0,602$, dimensi trait Conscientiousness $=0,851$, dimensi trait Extraversion $=0,771$, dimensi trait Agreeableness $=0,797$, dan dimensi trait Neuroticism $=0,831$.

\section{HASIL DAN PEMBAHASAN}

\section{Gambaran Responden}

Penelitian ini dilakukan pada 154 kasir yang bekerja di PT XYZ, baik di supermarket X maupun Y yang tersebar di Jakarta, Tangerang, dan Bekasi. Berikut gambaran responden yang berpartisipasi dalam penelitian ini

Tabel 1. Gambaran Responden Penelitian

\begin{tabular}{cccc}
\hline & Aspek & Jumlah & Persentase \\
\hline \multirow{2}{*}{ Jenis Kelamin } & Laki - Laki & 33 & $21,4 \%$ \\
& Perempuan & 121 & $78,6 \%$ \\
\multirow{2}{*}{ Toko } & Total & 154 & $100 \%$ \\
& Toko X & 39 & $25,3 \%$ \\
& Toko Y & 115 & $74,7 \%$ \\
Pendidikan & Total & 154 & $100 \%$ \\
& SMA/SMK Sederajat & 153 & $99,4 \%$ \\
& Diploma & 1 & $0,6 \%$ \\
Usia & Total & 154 & $100 \%$ \\
& $18-25$ & 131 & $85,1 \%$ \\
& $26-33$ & 22 & $14,2 \%$ \\
& $>33$ & 1 & $0,7 \%$ \\
& Total & 154 & $100 \%$
\end{tabular}

Sumber: Hasil Olah Data Peneliti

Dari tabel 1 dapat terlihat bahwa mayoritas responden penelitian ini adalah berjenis kelamin perempuan dengan persentase sebesar $78,6 \%$, berasal dari toko Y dengan persentase $74,7 \%$. Mayoritas responden penelitian, yaitu sebesar $99,4 \%$ memiliki tingkat pendidikan SMA/SMK/Sederajat. Rentang usia responden paling banyak di usia 18 tahun - 25 tahun yaitu sebesar $85,1 \%$.

\section{Gambaran Kepribadian}


Untuk melihat gambaran kepribadian kasir di setiap dimensi kepribadian, kategori yang digunakan adalah sebagai berikut: Rendah $=$ skor rata-rata $($ mean $)<3$, Tinggi $=$ skor rata-rata $($ mean $)>3$

Berikut diuraikan gambaran kepribadian kasir di PT XYZ. Kasir di PT XYZ memiliki trait extraversion yang tinggi $(\mathrm{M}=3,20)$, trait conscientiousness yang tinggi $(\mathrm{M}=3,17)$, trait openness to experience pada kategori rendah $(\mathrm{M}=2,98)$, trait agreeableness yang rendah $(\mathrm{M}=$ 2,78), dan trait neuroticism yang rendah $(\mathrm{M}=2,57)$. Dapat terlihat dari tabel 2.

Tabel 2. Gambaran Mean trait Kepribadian Kasir di PT XYZ

\begin{tabular}{ccc}
\hline Dimensi (Trait Kepribadian) & Mean (Skala 1 - 5) & Kategori \\
\hline Extraversion & 3,20 & Tinggi \\
Conscientiousness & 3,17 & Tinggi \\
Openness to Experience & 2,98 & Rendah \\
Agreeableness & 2,78 & Rendah \\
Neuroticism & 2,57 & Rendah \\
\hline
\end{tabular}

Sumber: Hasil Olah Data Peneliti

Berdasarkan penelitian ini ditemukan bahwa secara keseluruhan kasir di PT XYZ memiliki trait kepribadian extraversion dan trait conscientiousness yang tinggi, sementara trait kepribadian openness to experience, agreeableness, dan trait neuroticism berada pada kategori rendah.

Trait extraversion menggambarkan seseorang yang memiliki kehangatan pada orang lain, berperilaku ramah, mudah dan senang menjalin relasi dengan orang lain, bersemangat, serta selalu optimis. Bila dilihat dari pekerjaan kasir di industri retail dalam hal ini supermarket yang mengutamakan pelayanan pada pelanggan, trait ini mendukung kompetensi sosial yang perlu dimiliki kasir. Trait ini mendukung tugas kasir yaitu memberikan pelayanan pada transaksi berbelanja pelanggan. Kasir di PT XYZ akan mampu untuk bersikap ramah, yaitu dengan memberikan senyuman, serta menyapa pelanggan yang berbeda-beda yang berbelanja di supermarket PT XYZ.

Trait yang memiliki nilai mean juga pada kategori tinggi adalah conscientiousness. Trait ini dicirikan dengan individu yang pekerja keras, taat pada aturan dan norma/disiplin, teratur, memiliki perencanaan yang matang, serta bertanggung jawab. Trait ini mendukung pekerjaan sebagai kasir yang dituntut untuk mampu bekerja secara teratur dan rapi. Kasir yang bertanggung jawab pada transaksi keuangan di proses akhir berbelanja pelanggan, pasti dituntut untuk rapi, teratur, dan teliti. Dengan trait ini, kasir di PT XYZ akan mampu melaksanakan pekerjaannya dengan baik. Kasir akan tertib dalam mengelola berkas transaksi belanja pelanggan, melakukan proses scanning barcode dan packing barang belanjaan pelanggan, serta mampu menjaga kerapihan area kassa.

Trait yang berikutnya adalah trait openness to experience. Orang dengan trait ini digambarkan sebagai orang yang memiliki rasa ingin tahu yang besar, kreatif, suka berimajinasi, dan terbuka terhadap ide/gagasan yang baru. Orang - orang dengan trait openness to experience yang tinggi 
cenderung kurang menyenangi pekerjaan yang bersifat rutinitas dan teratur. Hasil penelitian menunjukkan kasir di PT XYZ memiliki trait openness to experience pada kategori rendah. Hal ini mendukung sifat pekerjaan kasir yang memang bersifat rutinitas pada transaksi belanja pelanggan, dengan demikian kasir akan merasa nyaman dengan pekerjaannya yang monoton.

Berikutnya adalah trait agreeableness, trait ini biasanya dikaitkan dengan keterampilan interpersonal. Orang dengan trait ini cenderung dilihat sebagai seseorang yang ramah, tidak menuntut, menghindari konflik, penyabar, dan cenderung untuk mengikuti orang lain. Dalam relasi dengan orang lain, orang dengan tingkat agreeableness tinggi, ketika dihadapkan pada konflik akan cenderung menurunkan self esteem mereka. Sedangkan orang-orang dengan tingkat agreeableness yang rendah cenderung untuk lebih agresif dan kurang kooperatif. Pada pekerjaan sebagai kasir seringkali pelanggan mengutarakan keluhan pada saat berlangsung proses transaksi, misalnya terjadi antrian panjang, perbedaan harga, serta situasi lain yang berpotensi terjadi konflik. Hasil penelitian ini menunjukkan kasir di PT XYZ memiliki trait kepribadian agreeableness pada kategori rendah, hal ini kurang mendukung pekerjaannya sebagai kasir sehingga kasir di PT XYZ cenderung akan kurang sabar dalam mendengarkan keluhan pelanggan dan akan cenderung kurang berusaha memahami pelanggan.

Trait kepribadian yang terakhir adalah neuroticism. Berbeda dengan empat trait kepribadian lainnya, pada trait neuroticism akan dinilai positif jika berada dalam kategori rendah. Hasil penelitian ini menunjukkan kasir di PT XYZ memiliki trait neuroticism pada kategori rendah. Dengan demikian kasir akan cenderung memiliki emosi yang stabil, kasir akan mempunyai level toleransi terhadap stress yang cukup baik, mereka akan berusaha mengatasi permasalahan dan tidak menghindari permasalahan. Hal ini tentu saja mendukung pekerjaannya karena profesi kasir yang rentan terhadap stress. Kasir merupakan salah satu posisi di supermarket yang memiliki tingkat stress tinggi, mereka dituntut bekerja secara teliti, cepat, namun juga harus ramah pada pelanggan. Posisinya yang berada di akhir aktivitas berbelanja pelanggan memastikan semua pelanggan akan berinteraksi dengannya, sehingga beban pekerjaan mereka cenderung lebih banyak dibandingkan posisi lain.

\section{KESIMPULAN DAN SARAN Kesimpulan}

Penelitian yang dilakukan terhadap 154 orang kasir di PT XYZ menunjukkan bahwa partisipan penelitian memiliki trait kepribadian extraversion dan trait kepribadian conscientiousness yang tinggi. Sementara trait kepribadian openness to experience, trait kepribadian agreeableness, serta trait kepribadian neuroticism yang rendah. Hasil penelitian ini menunjukkan bahwa kasir di PT XYZ memiliki gambaran kepribadian tertentu, yang mungkin berbeda dengan di perusahaan lain dan juga berbeda dari profesi lainnya.

\section{Saran}

Dalam menjalankan suatu jabatan diperlukan kesesuaian antara kepribadian dan karakteristik pekerjaannya. Hasil dari penelitian ini secara teoritis dapat berkontribusi pada literatur tentang kepribadian terutama pada profesi kasir. Secara praktis hasil dari penelitian menunjukkan bahwa profesi kasir memiliki gambaran kepribadian khas yang dapat menunjang pekerjaannya. Hasil penelitian ini dapat digunakan sebagai rekomendasi terutama bagi PT XYZ mengenai gambaran 
kepribadian kasirnya saat ini, sehingga ke depannya dapat melakukan proses seleksi yang lebih mendalam agar dapat diperoleh calon kasir dengan gambaran kepribadian tertentu yang sesuai dengan karakteristik pekerjaannya. Di satu sisi dengan seleksi dan mendapatkan orang yang tepat akan mampu membuat kasir berperilaku kerja semakin produktif dan menekan perilaku yang kurang produktif.

\section{Ucapan Terima Kasih}

Peneliti mengucapkan terima kasih pada manajemen PT XYZ yang sudah memberikan ijin pada peneliti melakukan pengambilan data penelitian. Peneliti juga mengucapkan terimakasih dan apresiasi pada kasir yang telah bersedia menjadi responden penelitian ini.

\section{REFERENSI}

Arora, R., \& Rangnekar, S. (2016). The interactive effects of conscientiousness and agreeableness on career commitment. Journal Of Employment Counseling, 53(1), 14-29. doi:10.1002/joec.12025

Feist, J., \& Feist, J.G. (2006).Theories of personality, seventh edition. New York: The McGrawHill Companies.

Giffen, R. (2015). Organizational culture and personality type: relationship with personorganization fit and turnover intention. Graduate Theses and Dissertations.Paper 14387. Retrieved from http://lib.dr.iastate.edu/cgi/viewcontent.cgi?article=5394\&context=etd

Kovach, Christine R, PhD,R.N., F.A.A.N., Simpson, Michelle R,PhD., R.N., Reitmaier, Amy B,M.S., R.N., Johnson, A., B.A., \& Kelber, S. T., M.S. (2010). Do personality traits predict work outcomes of certified nursing assistants?. Research in Gerontological Nursing, 3(4), 253-61. doi:http://dx.doi.org/10.3928/19404921-20100330-03

Opie, T. J., \& Henn, C. M. (2013). Work-family conflict and work engagement among mothers: Conscientiousness and neuroticism as moderators. SA Journal of Industrial Psychology, 39(1), 1-12. Retrieved from https://search.proquest.com/docview/1440187964 accountid=25704

Rothmann, S, \& Coetzer, E. P. (2003). The big five personality dimensions and job performance. SA Journal of Industrial Psychology.29. doi:10.4102/sajip.v29i1.88

Sumintardja, E.N. (2009). Tes Lima Dimensi. Tidak dipublikasikan. 